\title{
Modified leprosy elimination campaign (MLEC) for case detection in a remote tribal area in the State of Orissa, India
}

\author{
P.V. RANGANADHA RAO, R.A. BHUSKADE \& \\ K.V. DESIKAN \\ Lepra India, PB No. 1518, Krishnapuri Colony, West Maredpally, \\ Secunderabad 500 026, India
}

Accepted for publication 12 July 2000

\begin{abstract}
Summary A leprosy project was established in a difficult to reach area under guidelines of Government of India. The leprosy services were provided by Koraput Leprosy Eradication Project (KORALEP) and general health services by Primary Health Care (PHC). Leprosy elimination campaigns (LECs) were suggested by WHO to detect more cases in the community. A modified leprosy elimination campaign (MLEC), carried out utilizing the services of primary health care workers is discussed in this paper. Apart from the trained health workers, Anganwadi workers along with some literate people from the district were also included in the search teams. In all, 1543 cases were shortlisted from the suspects identified and on re-examination 576 cases were confirmed as active cases. Sixty percent of the cases detected were very early cases with two to three skin lesions. This could be achieved with a very brief training of health workers and involving village voluntary workers. MLEC was found to be a useful tool for case finding in such areas.
\end{abstract}

\section{Introduction}

A leprosy project was established in 1992 in a hilly tribal area of Orissa State in India. The tribal people live on forest produce and their main occupation is agriculture. They move into deep forests or to areas where agriculture is possible in the forest and mountains. The terrain is hilly and criss-crossed by rivers and rivulets. Half of the villages are approachable only by foot.

The leprosy project was planned with the components of survey, education and treatment (SET) according to guidelines framed by the Government of India. ${ }^{1}$ In a situation where the prevalence rates are high and population coverage is poor, WHO suggested Leprosy Elimination Campaigns (LECs). These were planned for rapid case finding and improving the level of awareness among people. The LECs are slightly modified in India depending on various local factors and conditions and the availability of trained personnel and required Seconderabad 500 026, India (e-mail: lepra@lepraindia.org) 
Table 1. Details of the area and personnel involved

\begin{tabular}{lll}
\hline & & \\
1 & Project & KORALEP \\
2 & Area & $14494 \mathrm{~km}^{2}$ \\
3 & Population & 1.47 million \\
4 & No. villages and hamlets & 6545 \\
5 & Average population of hamlets & $150(15-1500)$ \\
6 & No. of PHCs & 88 \\
7 & No. of MPHWs & 676 \\
8 & No. of Anganwadi workers & 1869 \\
9 & No. of voluntary workers & 2925 \\
\hline
\end{tabular}

inf rastructure. Modified LECs (MLEC) were planned to involve staff from the general health care system. The experience with MLEC in a predominantly tribal area of Orissa, India geographically inaccessible and culturally different is described in this paper.

\section{AREA OF OPERATION AND PERSONNEL INVOLVED}

The project area covers nearly 1.5 million populations in Koraput and Malkangiri districts in the western part of Orissa, where $75 \%$ of the people are tribal. The villages are associated with small hamlets, which are scattered on the hilltops and valleys. The average population of a village is 1500 and that of a hamlet 150 . There are 16 different tribes living in many of the 1940 villages, using 12 different dialects, which are very difficult for the health staff to understand. There are three main rivers and many tributaries crossing the district, which flood during monsoon months and disrupt road communications in the district.

Leprosy services in the district are provided by Koraput Leprosy Eradication Project (KORALEP) of Lepra India, with two medical of ficers and 30 paramedical workers (PMWs), each covering a population of 50,000.

General health care is provided by the state Government in 88 primary health care centers (PHC). Each centre has a medical officer and 1-20 multi-purpose health workers (MPHW) depending on the population covered by the centre. The state Government has employed female grass-root level workers under an Integrated Child Development Scheme (ICDS), each worker covering 500-1000 population. The workers are called Anganwadi workers. For the MLEC, in addition to health care workers, voluntary workers such as students, youth club members and some literate persons of the village were also involved. Details of the area and personnel involved employed for the MLEC programme are given in Table 1.

\section{Materials and methods}

The MLEC was planned to cover all the villages and hamlets in the district. The method of execution of the programme was to screen the entire population, identify persons with suspected signs of leprosy, have the suspected cases diagnosed by the confirmation team and register the confirmed cases for treatment.

The MPHWs were given 3 days training to enable them to suspect leprosy. Anganwadi workers and other voluntary workers were given 1 day's training to support MPHWs. Each MPHW had to visit 8-10 villages/hamlets. In each village a search team was formed with a 
Table 2. Findings on previous surveys

\begin{tabular}{lccc}
\hline Examination status in previous surveys & MB & PB & Total \\
\hline Not examined & $84(48 \%)$ & $173(43 \%)$ & $257(45 \%)$ \\
Examined but free of leprosy & $90(52 \%)$ & 229 & $319(55 \%)$ \\
Total & 174 & 402 & 576 \\
& & & \\
\hline
\end{tabular}

local Anganwadi worker and one or more village voluntary workers. The team had to complete the search operation with in 6 days. On the first day, the locally formed team met with the important persons in the village, seeking their cooperation. The team visited every house in all villages and hamlets. Every household contacted by the members of the team was given a visit card (chirkut), which was later collected by the members of the confirmation team on their follow-up visit to keep account of household visits. The confirmation team consisted of KORALEP staff and medical officer of PHCs. They received a list of suspects from the search teams and examined each suspect to confirm or rule out leprosy.

\section{Results}

The search team visited all the houses allotted in the villages and hamlets and identified 13,907 suspects. These persons were subjected to preliminary examination by 70 teams comprising of PHC medical officers and MPHWs. Of these suspected persons, 1543 were short-listed. These short-listed suspects were re-examined by the confirmation team and 576 persons were found to have leprosy. The survey registers were checked to find out whether any of these 576 patients were examined during previous surveys. Table 2 gives details.

It can be seen that 257 (45\%) of the patients diagnosed in the MLEC were not examined in previous surveys. The survey registers showed that they had migrated to the villages/hamlets after the last survey completed 2 years earlier. 319 patients were examined earlier and diagnosis was missed. The details of these 319 patients are presented in Table 3. Further analysis of these 319 patients showed that $73 \%$ had obviously been missed since the previous survey. The remaining $85(27 \%)$ developed the disease subsequent to that survey.

The clinical details of 576 patients detected by the MLEC programme are analysed and presented in Table 4 . Sixty percent of the cases were very early, with one to three lesions. There were only 62 cases with obvious deformity. It is interesting that the workers were able to identify cases with diffuse skin infiltration. There were as many as $32(5.5 \%)$ bacteriologically positive cases.

Table 3. Duration of disease in missed patients

\begin{tabular}{llrr}
\hline Duration in years & MB & PB & Total \\
\hline$>2$ years & $68(76 \%)$ & $166(72 \%)$ & $234(73 \%)$ \\
$<2$ years & $22(24 \%)$ & $63(28 \%)$ & $85(27 \%)$ \\
& 90 & 229 & 319 \\
\hline
\end{tabular}


Table 4. Clinical details of patients detected in MLEC

\begin{tabular}{|c|c|c|c|c|c|c|c|c|c|c|}
\hline & \multicolumn{4}{|c|}{ Number of patches } & \multirow{2}{*}{$\frac{\text { Other features }}{\text { Infiltration }}$} & \multicolumn{3}{|c|}{ Deformity } & \multicolumn{2}{|c|}{ Stain smears } \\
\hline & 1 & $2-3$ & $4-5$ & $>5$ & & G0 & GI & GII & Positive & Negative \\
\hline MB & - & - & 35 & 124 & 15 & 60 & 56 & 58 & 32 & 142 \\
\hline PB & 38 & 347 & 17 & - & - & 394 & 4 & 4 & - & 402 \\
\hline Total & 38 & 347 & 52 & 124 & 15 & 454 & 60 & 62 & 32 & 544 \\
\hline
\end{tabular}

While analysing the patient cards, it was found that 29 patients had at least one of the family members as patients who could possibly have been a source of infection.

\section{Discussion}

The study shows that MLEC is an effective method of detecting cases in 'difficult-to reach' populations as it is in the plains and other parts of India. The MLEC has made the general public sensitive to the problem of leprosy. The approach involving the MPHWs and Anganwadi workers initially with an awareness generation programme, followed by visits to the village in groups, has sensitized the people. The response of the community was very helpful in conducting the programme successfully.

By the quick methods of search adopted, the search teams were able to visit a large majority of houses and conduct an enquiry survey of about $70 \%$ of the population. The 576 patients detected gave a new case detection rate (NCDR) of 3.9/10,000, compared with NCDR of $8 \cdot 6 / 10,000$ in the project adopting different detailed methods of case detection over a period of 150 working days. Nearly half of the case detection was achieved by adopting MLEC in a short span of 6 days.

Thirty-eight single lesion cases and 347 cases of two or three lesions were detected by MLEC. Obvious leprosy cases with visible deformity were only 62 . It is significant to note that even briefly trained Anganwadi workers and village voluntary workers could detect very early cases. A further 15 patients with only oily and shiny skin were also identified during the campaign. A total of 32 out of 576 patients were bacteriologically positive, indicating that by adapting special campaigns, skin smear positive cases can also be detected.

MLEC has incidentally helped in exposing the MPHWs and other health care staff to leprosy services. This could have a great impact in future integration of leprosy work into general health care services.

The success of this MLEC programme could be attributed to the very intensive short time frame, which created interest in the community and health workers. Further, having worked with tribal people for a number of years, it has been our experience that the tribal people would at first distrust outsiders, since they are very shy and elusive. However, after getting to know us, they overcome their apprehension and become extremely cooperative, showing implicit faith in the services rendered.

MLEC could thus be an effective tool in such tribal areas, where difficult geographical factors, migration, cultural and poor health-seeking behaviour hinder the routine health programmes. Therefore, MLEC could be a suitable supplement not only to routine case 
finding in the vertical leprosy programme at present, but also in an integrated approach with general health services in future.

\section{Further reading}

Barua S, Wakai S, Shwe T, Umenai T. Leprosy elimination through integrated basic health services in Myanmar: the role of midwives. Lepr Rev, 1999; 70: 174-179.

DGHS. Guidelines for multi-drug treatment in endemic districts, NLEP in India. Leprosy Division, Directorate General of Health Services, New Delhi, India, 1993.

Dharmashaktu NS, Barkakaty BN, Patnaik P, Arif MA. Progress towards elimination of leprosy as a public health problem in India and role of modified leprosy elimination campaign. Lepr Rev, 1999; 70: 430-439.

Patnaik PKB. Modified leprosy elimination campaign (MLEC) in the state of Orissa, India. Lepr Rev, 1999; 70: 440447.

Rajdekar MP, Thakar TK, Pharande AM et al. Hidden sources of infection in unapproachable area. Ind J Lepr, 1997; 69: 169-171.

Vijayakumaran P, Mahipathy PV, Misra R Ket al. Hidden cases of leprosy (in prison). Ind J Lepr, 1997; 69: 247-250. 